\title{
Retention Characteristics of CBTi144 Thin Films Explained by Means of X-Ray Photoemission Spectroscopy
}

\author{
G. Biasotto, ${ }^{1}$ A. Z. Simões, ${ }^{2}$ C. S. Riccardi, ${ }^{1}$ M. A. Zaghete, ${ }^{1}$ E. Longo, ${ }^{1}$ and J. A. Varela ${ }^{1}$ \\ ${ }^{1}$ Laboratório Interdisciplinar em Cerâmica, Departamento de Físico-Química, Instituto de Química, Universidade Estadual Paulista, \\ R. Francisco Degni, s/n, Bairro Quitandinha, 14801-970 Araraquara, SP, Brazil \\ ${ }^{2}$ Universidade Federal de Itajubá-Unifei, Campus Itabira, Rua São Paulo, 377, 35900-373 Bairro Amazonas-Itabira MG, Brazil
}

Correspondence should be addressed to A. Z. Simões, alezipo@yahoo.com

Received 5 February 2010; Accepted 6 April 2010

Academic Editor: Zoe Barber

Copyright (c) 2010 G. Biasotto et al. This is an open access article distributed under the Creative Commons Attribution License, which permits unrestricted use, distribution, and reproduction in any medium, provided the original work is properly cited.

\begin{abstract}
$\mathrm{CaBi}_{4} \mathrm{Ti}_{4} \mathrm{O}_{15}$ (CBTi144) thin films were grown on $\mathrm{Pt} / \mathrm{Ti} / \mathrm{SiO}_{2} / \mathrm{Si}$ substrates using a soft chemical solution and spin-coating method. Structure and morphology of the films were characterized by the X-ray Diffraction (XRD), Fourier-transform infrared spectroscopy (FT-IR), Raman analysis, X-ray photoemission spectroscopy (XPS), and transmission electron microscopy (TEM). The films present a single phase of layered-structured perovskite with polar axis orient. The $a / b$-axis orientation of the ferroelectric film is considered to be associated with the preferred orientation of the Pt bottom electrode. XPS measurements were employed to understand the nature of defects on the retention behavior of CBTil44 films. We have observed that the main source of retentionfree characteristic of the capacitors is the oxygen environment in the CBTi144 lattice.
\end{abstract}

\section{Introduction}

Bismuth-based layer-structured ferroelectrics (BLSFs) are attractive materials because of their high potential for application to ferroelectric random access memories (FeRAM), piezoelectric resonators, and dynamic random access memories $[1,2]$. $\mathrm{CaBi}_{4} \mathrm{Ti}_{4} \mathrm{O}_{15}$ is a member of the Aurivillius family, $\left(\mathrm{Bi}_{2} \mathrm{O}_{2}\right)^{2+}\left(\mathrm{A}_{n-1} \mathrm{~B}_{n} \mathrm{O}_{n+1}\right)^{2-}$, in which A represents mono-, di-, tri-valent ions and $\mathrm{B}$ represents tetra-, pentaor hexavalent ions. The compounds such as $\mathrm{PbBi}_{4} \mathrm{Ti}_{4} \mathrm{O}_{15}$, $\mathrm{BaBi}_{4} \mathrm{Ti}_{4} \mathrm{O}_{15}$, and $\mathrm{SrBi}_{4} \mathrm{Ti}_{4} \mathrm{O}_{15}$, which have the $n$ value of 4 , have been studied for their anisotropic ferroelectricity [3-7]. CBTi144 is characterized by its high Curie point of about $790^{\circ} \mathrm{C}$ and therefore is expected to be useful for special applications at relatively high temperature $[8,9]$. Compounds in the family have anisotropic ferroelectricity, which is strongly associated with the crystal structure, especially the compounds with $n$ equal to an even number which have no polarization along the $c$ axis because there is a mirror plane perpendicular to the axis $[10,11]$. The polarization of the compounds is along the $a$ axis. Therefore, the thin films with $a$-axis orientation are preferred for use in many kind of devices, such as ferroelectric random access memories, piezoelectric microactuators, and resonators. The crystallinity and orientation of the $\mathrm{Pt}$ bottom electrodes were found to affect the phase transition of paraelectric to ferroelectric in CBTi144 thin films [12].

CBTi144 thin films have been synthesized via the chemical solution deposition techniques, such as the sol-gel and metalorganic decomposition method, and characterized for application to integrated systems such as ferroelectric random access memories because of their high resistance to fatigue and low processing temperature [13-18]. Also, other technique which is being used nowadays consists of a simple hydroxides precursor for the synthesis of bulk compounds at very low temperatures. This process has been used by us successfully to prepare many technologically important compounds [19-25]. The method is easily amenable for large-scale production and relatively economical. The bulk CBT powders can be used as a target for DC sputtering and laser ablation methods for the preparation of corresponding thin films.

Among various methods such as MOCVD, pulsed laser deposition, and sol-gel, the polymeric precursor method has a better potential for technological applications, because of its precise control of composition and homogeneity 
and good conformality [26]. The overall process consists of preparing a coating solution based on metallic citrate polymerization [25]. The precursor film is deposited by dip or spin coating and then treated to eliminate the organic material and synthesize the desired phase.

In a ferroelectric material, the fatigue and retention endurance properties deteriorate with the increase of switching pulse width. Nowadays, X-ray photoemission spectroscopy (XPS) which is sensitive to local electronic structure of constituent atoms and is among the most suitable technique for investigating the effects of surface layers on the polarization properties and ferroelectric behavior of polycrystalline ceramics [27].

Earlier work [28] proposed that the self-regulating $\left(\mathrm{Bi}_{2} \mathrm{O}_{2}\right)^{2+}$ layer in SBT can compensate the space charge near the electrode and plays a crucial role in its fatigue-free behavior, whereas another Aurivillius compound, $\mathrm{Bi}_{4} \mathrm{Ti}_{3} \mathrm{O}_{12}$ (BIT), [29] exhibits a severe fatigue failure. From recent $\mathrm{X}$-ray photoelectron spectroscopy (XPS) studies of BIT ceramics, [30] and (001) epitaxy thin lms of SBT and BIT, Park et al. [31] argued that the difference in oxygen stability in the perovskite layer between SBT and BIT should be related to their distinct fatigue resistance, in addition to the universally accepted role of the $\left(\mathrm{Bi}_{2} \mathrm{O}_{2}\right)^{2+}$ layer. In another investigation on the different fatigue behaviors of two isostructural Aurivillius compounds, $\mathrm{SBT}$ and $\mathrm{Bi}_{3} \mathrm{TiTaO}_{9}$, [32] Kang et al. more directly suggested that a Bi-free perovskite layer enhances its oxygen stability and, hence, leads to the fatigue-free property of SBT. This result concurrently supports the qualitative fatigue-free model inferred from previous XPS measurements. In this way, the main goal of this work is to employ XPS studies to explore the nature of defects in the crystal lattice of ferroelectric material and probe their surface characteristics.

\section{Experimental}

Calcium citrate (Synth), titanium isopropoxide (Hulls AG) and bismuth oxide (Aldrich) were used as raw materials. The precursor solutions of calcium, bismuth, and titanium were prepared by adding the raw materials to ethylene glycol and concentrate aqueous citric acid under heating and stirring. Appropriate quantities of $\mathrm{Ca}, \mathrm{Ti}$, and $\mathrm{Bi}$ solutions were mixed and homogeneized by stirring at $90^{\circ} \mathrm{C}$. The molar ratio of metal:citric acid: ethylene glycol was $1: 4: 16$. The viscosity of the resulting solution was adjusted to 20 $\mathrm{cP}$ by controlling the water content using a Brookfield viscosimeter. The CBTil44 thin films were spin coated on $\mathrm{Pt} / \mathrm{Ti} / \mathrm{SiO}_{2} / \mathrm{Si}$ substrates by a commercial spinner operating at 5000 revolutions/min for $30 \mathrm{~s}$ (spin coater KW-4B, Chemat Technology). In this work, an excess of $5 \%$ wt of Bi was added to the solution aiming to minimize the bismuth loss during the thermal treatment. Without this additional bismuth the pure phase could not be obtained as was reported in literature [33]. The thin films were annealed at $700^{\circ} \mathrm{C}$ for 2 hours in the conventional furnace. Through this process, we have obtained thickness values of about $310 \mathrm{~nm}$ for CBTi144, reached by repeating the spin-coating and heating treatment

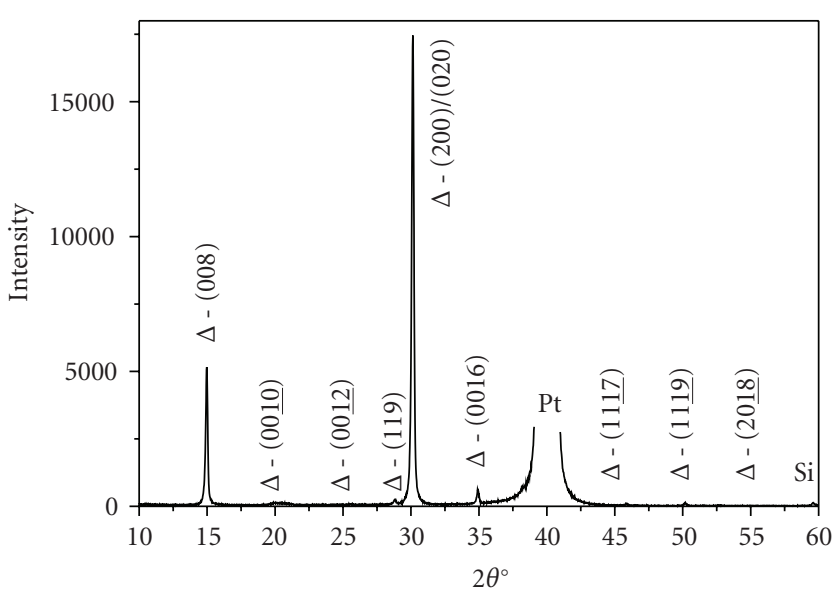

$\Delta-$ CBT144

FIgure 1: X-ray diffraction for CBTi144 thin film deposited on (100) $\mathrm{Pt} / \mathrm{Ti} / \mathrm{SiO}_{2} / \mathrm{Si}$ substrate at $700^{\circ} \mathrm{C}$ for 2 hours.

cycles. The thickness of the annealed films was studied using scanning electron microscopy (Topcom SM-300) by looking at the transversal section. In this case, backscattering electrons were used.

The preparation of the CBTi144 deposition solution was described in detail elsewhere [33]. Phase analysis of the films was performed at room temperature by X-ray diffraction (XRD) using a Bragg-Brentano diffractometer (Rigaku 2000) and $\mathrm{CuK} \alpha$ radiation. Infrared analysis was performed on (Bruker-Equinox 55, Germany) Fourier transformed infrared spectrometer (FT-IR), using a $30^{\circ}$ specular reflectance accessory. The FT-IR reflectance spectra of the thin films were recorded at room temperature in the 400 $1200 \mathrm{~cm}^{-1}$ range. Raman measurements were performed using an ISA T 64000 triple monochromator. An optical microscope with $80 \mathrm{X}$ objective was used to focus the 514.5$\mathrm{nm}$ radiation from a Coherent Innova $99 \mathrm{Ar}^{+}$laser on the sample. Since XPS is sensitive to local electronic structure of constituent atoms, it can be used to probe the chemical nature and to investigate differences in the defect charge of the films. Photoelectron spectra of Bi $4 \mathrm{f}, \mathrm{Ti} 2 \mathrm{p}$, and Ca $2 p$ core levels were recorded using a computer controlled data collection system. The electron analyzer was set at pass energy of $10 \mathrm{eV}$. A PHI-5702 multifunction X-ray photoelectron spectrometer was used, working with an $\mathrm{Al}-$ $\mathrm{K} \alpha \mathrm{X}$-ray source of $29.35 \mathrm{eV}$ passing energy. The pressure in the chamber during the experiments was about $4 \cdot 5 \cdot 10^{-9}$ Torr. Calibration of binding energy scale was controlled using the Ol's line, which appears in the photoelectron spectra of the as-received samples.

The ferroelectric properties of the capacitors were measured by a Radiant Technology Tester RT6000 A in a virtual ground mode. Retention characteristics of the films were measured at room temperature using a Radiant Technology RT6000 A test system. We have measured independently the time-dependent changes of $\mathrm{P}^{*}$ (switched polarization), and $\mathrm{P}^{\wedge}$ (nonswitched polarization). 


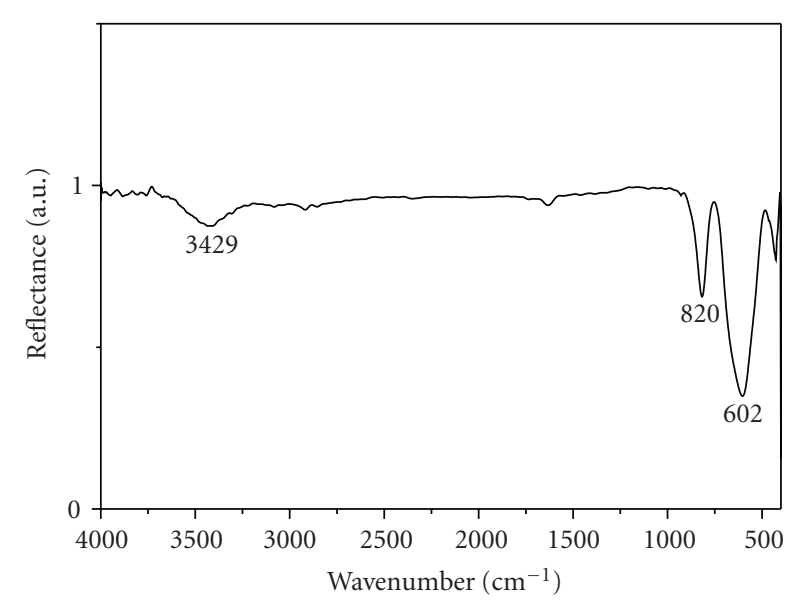

FIGURE 2: FT-IR spectra of CBTi144 film annealed deposited by the soft chemical method at $700^{\circ} \mathrm{C}$ for 2 hours.

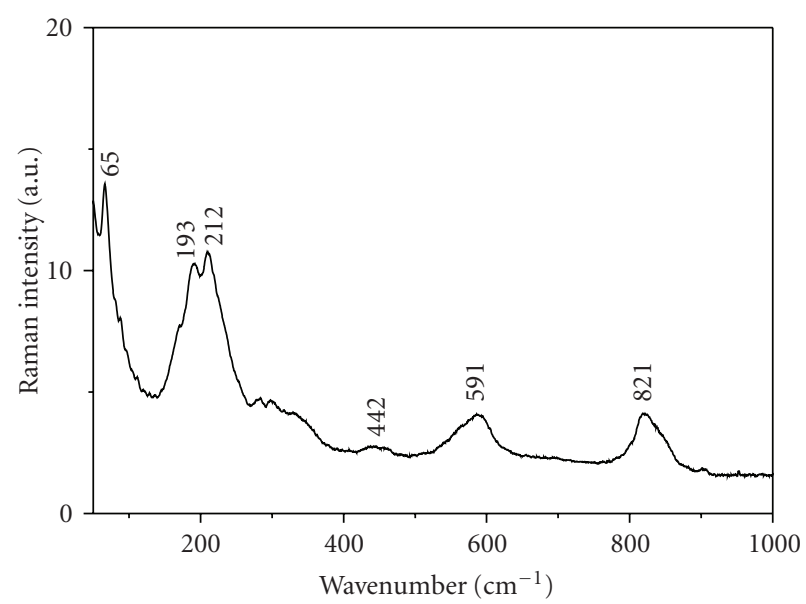

FIgure 3: Micro Raman spectra for CBTi144 film deposited by the soft chemical method at $700^{\circ} \mathrm{C}$ for 2 hours.

\section{Results and Discussion}

Figure 1 shows the XRD pattern of CBTi144 thin film annealed at $700^{\circ} \mathrm{C}$ for 2 hours. CBTilu4 films on the platinum coated silicon substrates showed a high intensity of the $(200) /(020)$ diffraction line compared to the other lines, although the (200) and (020) diffraction lines could not be distinguished from each other. The characteristic orientation is considered to be due to good matching of atomic arrangements in CBTi144 (100)/(010) and underlying Pt planes. Characteristic peak for platinum coated silicon (100) substrates was observed in the range of $38^{\circ}<2 \theta<41^{\circ}$. Since the lattice constants of $a$ (or $b$ ) and $c$ of the CBTil44 film is close to 0.5417 and $4.086 \mathrm{~nm}$, the lattice mismatches between the ferroelectric phase and $\mathrm{Pt}$ lattice were given as remarkably small as $1.1 \%$ and $4.9 \%$, respectively. The characteristic $(100) /(010)$ orientation of the CBTil44 film is based on the good lattice matching of CBTi144 (001) with Pt (100) planes.

The FT-IR absorption spectrum of the CBTi144 film is shown in Figure 2. Measurements were carried out in

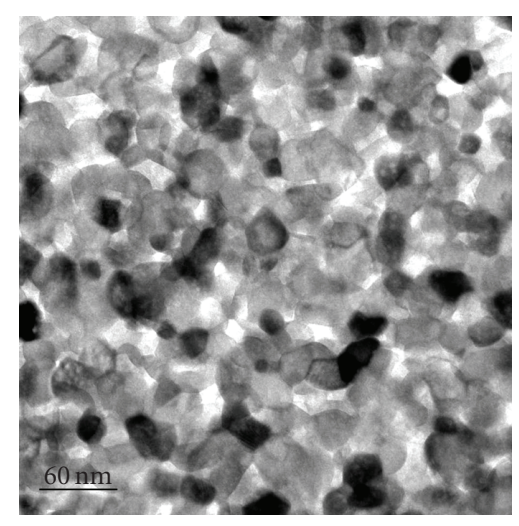

(a)

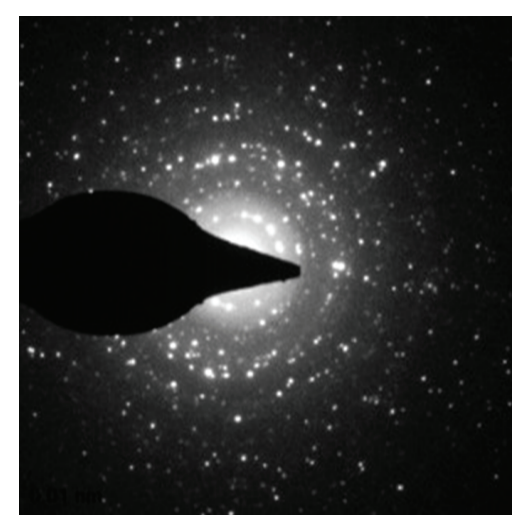

(b)

FIGURE 4: (a) A plan-view TEM micrograph and (b) Selected area diffraction (SAD) pattern for CBTi144 film deposited by the soft chemical method at $700^{\circ} \mathrm{C}$ for 2 hours.

reflection mode. A broad absorption peak of the $\mathrm{BO}_{6}$ stretching mode was observed at $550-740 \mathrm{~cm}^{-1}$ suggesting the formation of pure perovskite phase [34]. The very small absorption band at $1439 \mathrm{~cm}^{-1}$ can be interpreted as $\mathrm{C}=\mathrm{O}$ vibration due to extremely small unavoidable traces of carbonate. Strong intense bands at 3772 and below $700 \mathrm{~cm}^{-1}$ were observed. The bands located at 3420 and $1615 \mathrm{~cm}^{-1}$ correspond to the $\nu(\mathrm{O}-\mathrm{H})$ mode of $(\mathrm{H}$-bonded $)$ water molecules and $\delta(\mathrm{OH})$, respectively. Residual water and hydroxy group are usually detected in the as-prepared samples and further heat treatment is necessary for their elimination.

Raman spectra of CBTi144 film evidenced vibrational modes located at $67,193,212,442,591$, and $821 \mathrm{~cm}^{-1}$ (Figure 3). The modes located below $200 \mathrm{~cm}^{-1}$ can be addressed to different sites occupied by bismuth within the perovskite layer. On the other hand, the vibrational modes located at 207, 442, 587, and $819 \mathrm{~cm}^{-1}$ result from the $\mathrm{TiO}_{6}$ octahedral $(\mathrm{Ti}=5$ or $\mathrm{Ti}=6)$. Slight changes which occur above $200 \mathrm{~cm}^{-1}$ can be associated to structural distortion and reduction of vibrations in the $\mathrm{TiO}_{5}$ octahedra. The position occupied by calcium on the bismuth site within the perovskite structure having marginal influence in the interactions between the $\left(\mathrm{Bi}_{2} \mathrm{O}_{2}\right)^{2+}$ layers and perovskite. 


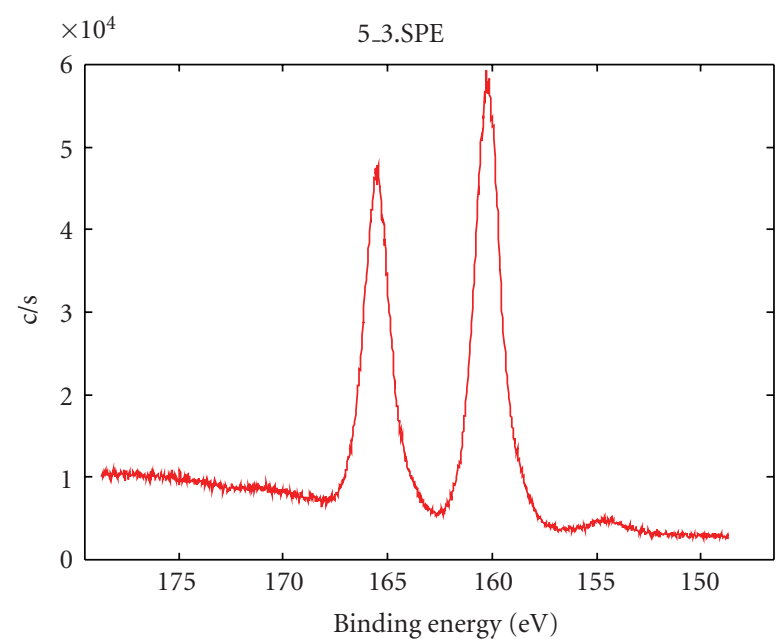

(a)

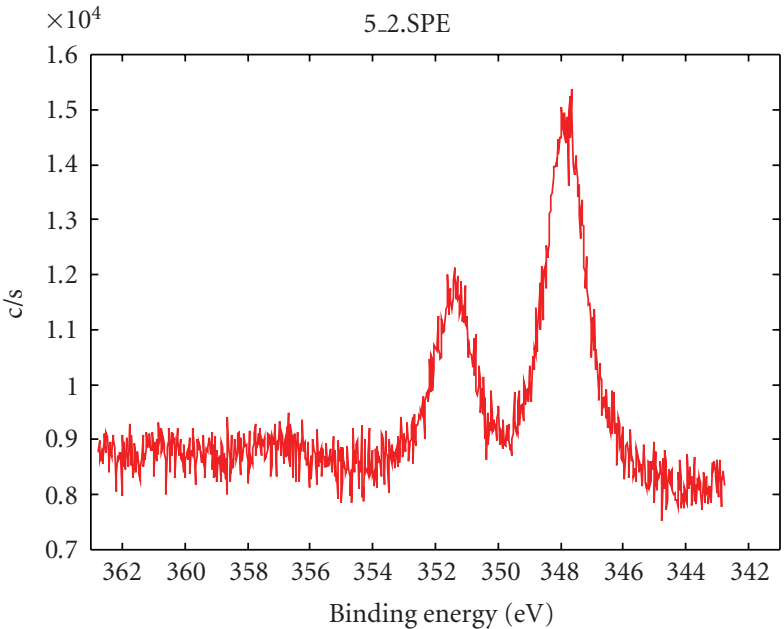

(b)

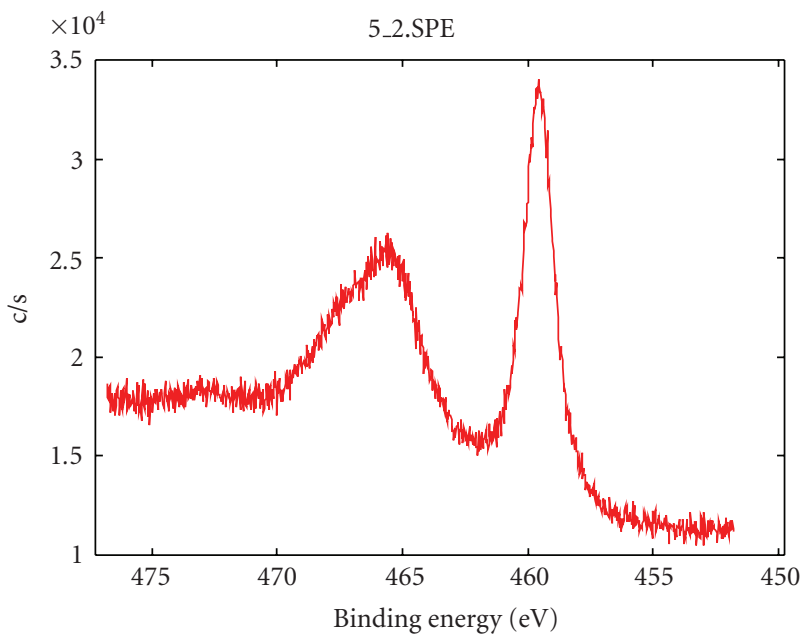

(c)

Figure 5: XPS spectra of (a) Bi 4f, (b) Ca 2p, (c) Ti 2p peaks for CBTi144 thin films deposited by the soft chemical method at $700^{\circ} \mathrm{C}$ for 2 hours.

A plan-view TEM image of the CBTi144 film shows the microstructure and the selected area diffraction (SAD) patterns (Figures 4(a) and 4(b)). It could be noticed the polycrystallinity of the grains in the plane of the films. Besides that, the diffraction patterns indicate strong randomness of atom position, as previous noted in the XRD data (Figure 4(b)). A detailed analysis reveals that the film is free of pyrochlore structure due to the suppression effect of the Pt bottom. This result is in agreement with those reported in the literature [35] and with those previously reported by our group [36]. Pores less than $10 \mathrm{~nm}$ in size are present within the grains and along the grain boundaries. Well-developed and uniform columnar grains of perovskite phase with an estimated size of about $46 \mathrm{~nm}$ were observed (Figure 4(a)). The low grain size results in a slower oxygen ion motion and consequently lower grain growth rate This implies that calcium substitution in the A site reduces the concentration of oxygen vacancies in the vicinity of $\mathrm{Bi}$ and Ti ions. When $\mathrm{Ca}$ is added in the system the $\mathrm{TiO}_{6}$ octahedral linked to $\mathrm{Bi}_{2} \mathrm{O}_{2}$ is not shrinked, allowing the movement of $\mathrm{Ti}^{4+}$ ions and thus improving the space charge compensation. This result is in agreement with the good ferroelectric response of CBTil44 thin films and can be related to reduction of oxygen vacancy acting as space charge which causes strong domain pinning and inhibits the poling of the film.

In order to gain further understanding on the defects created by crystallization of CBTi144 thin films, X-ray photoemission analysis was performed. Photoemission of $\mathrm{Bi}$ $4 \mathrm{f}, \mathrm{Ca} 2 \mathrm{p}$, Ti $2 \mathrm{p}$ core levels was performed and the results are shown in Figure 5. The photoemission spectra of Bi $4 \mathrm{f}$ core level indicates that the $7 / 2$ and $5 / 2$ spin-orbit double component are located approximately at 160.4 and $165.7 \mathrm{eV}$, respectively (Figure 5(a)). The spin-orbit splitting of Bi $4 \mathrm{f}$ core levels is around $5.3 \mathrm{eV}$. The binding energy of $\mathrm{Bi} 4 \mathrm{f}$ is not strong influenced by calcium addition indicating a reduction in the oxygen vacancy concentration in the system. This 


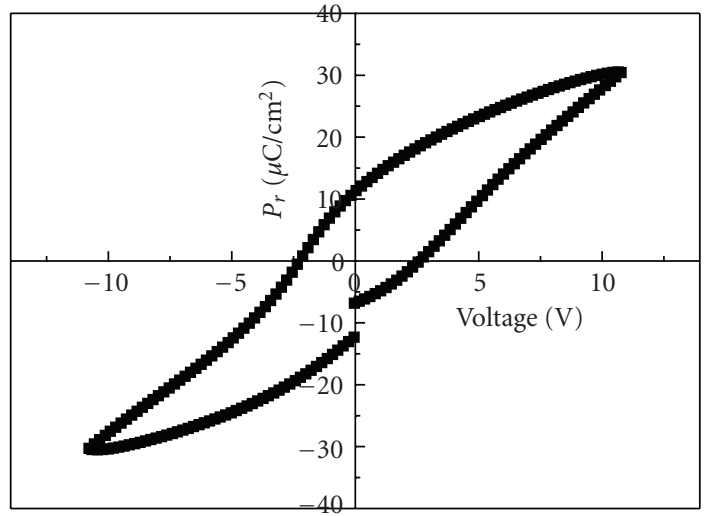

Figure 6: P-V hysteresis loop for CBTil44 thin film deposited on (100) $\mathrm{Pt} / \mathrm{Ti} / \mathrm{SiO}_{2} / \mathrm{Si}$ substrate at $700^{\circ} \mathrm{C}$ for 2 hours.

tendency to keep unchanged the binding energy suggests no fluctuations in the chemical valence of $\mathrm{Bi}$ and $\mathrm{Ti}$. That is to say, the chemical valence of $\mathrm{Bi}$ and $\mathrm{Ti}$ is +3 and +4 valence state, which implies that the substitution of calcium in the A site have influence in the concentration of oxygen vacancies in the vicinity of $\mathrm{Bi}$ and $\mathrm{Ti}$ ions. This explain that when $\mathrm{Ca}$ is added in the system, the $\mathrm{TiO}_{6}$ octahedral linked to $\mathrm{Bi}_{2} \mathrm{O}_{2}$ have no shrinks, allowing the movement of $\mathrm{Ti}^{4+}$ ions and thus affecting the space charge compensation. These results indicate that the environment of the oxygen ions near the $\mathrm{Ca}$ and $\mathrm{Bi}$ ions is different. The photoemission spectra of $\mathrm{Ca} 2 \mathrm{p}$ core levels indicates that the $3 / 2$ and $5 / 2$ spinorbit double component are located approximately at 347.8 and $351.3 \mathrm{eV}$, respectively (Figure 5(b)). Two types of spinorbit doublet were evident: one is the spin-orbit doublet of the $\mathrm{Ca} 2 \mathrm{p}$ core level and the other is that in another Ca oxide different from CBTi144. The photoemission spectra of $\mathrm{Ti} 2 \mathrm{p}$ core levels are also shown (Figure 5(c)). The Ti $2 p 3 / 2$ photoelectron peak appears in the XPS spectrum as a distinctively resolved feature at a binding energy position of $458.1 \mathrm{eV}$. The Ti $2 p$ peak is slightly broader suggesting some oxygen at the perovskite layers are not taken out. These experimental results imply that oxygen vacancies could not be induced in the neighborhood of the $\mathrm{Bi}$ and the Ti atoms.

Ferroelectricity of the calcium bismuth titanate thin films was observed with remanent polarization equal to $14 \mu \mathrm{C} / \mathrm{cm}^{2}$ and coercive field equal to $64 \mathrm{kV} / \mathrm{cm}$ (Figure 6). It can be also noted the absence of imprint which causes a significant shift along the electric field axis towards the positive side. This indicates that our films present a small concentration of space charges in the electrode-film interface. The $P_{r}$ and $E_{c}$ values were improved compared with the values obtained for CBTi144 thin films with random orientation [37]. The higher $P_{r}$ value suggests that the (100) orientation is preferred rather than the (010) orientation with respect to the present CBTil44 film.

It is retention failure of ferroelectric CBTil44 thin films that is related to oxygen vacancies present at the titaniumoxygen octahedral. Thus, to understand the retention failure in the layered perovskite materials is important to evaluate

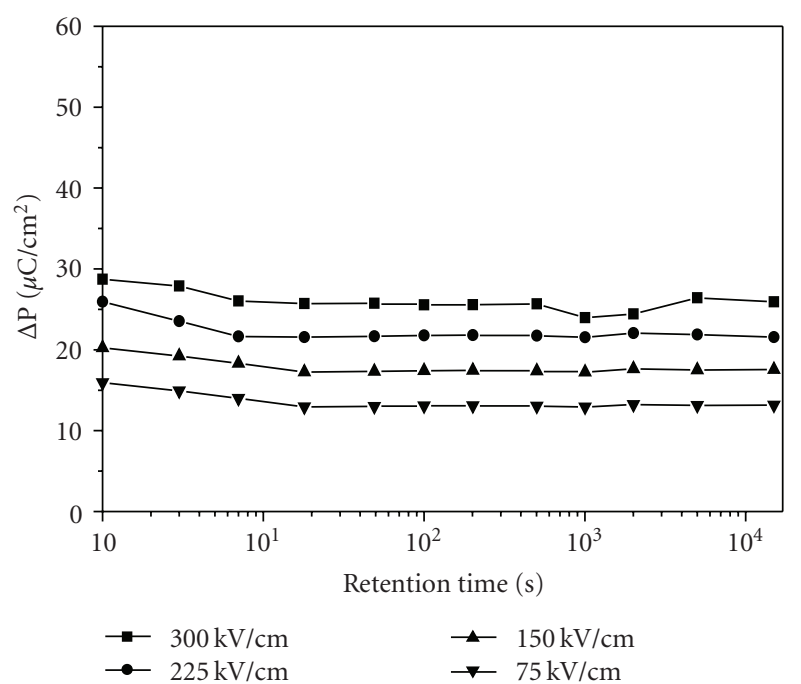

(a)

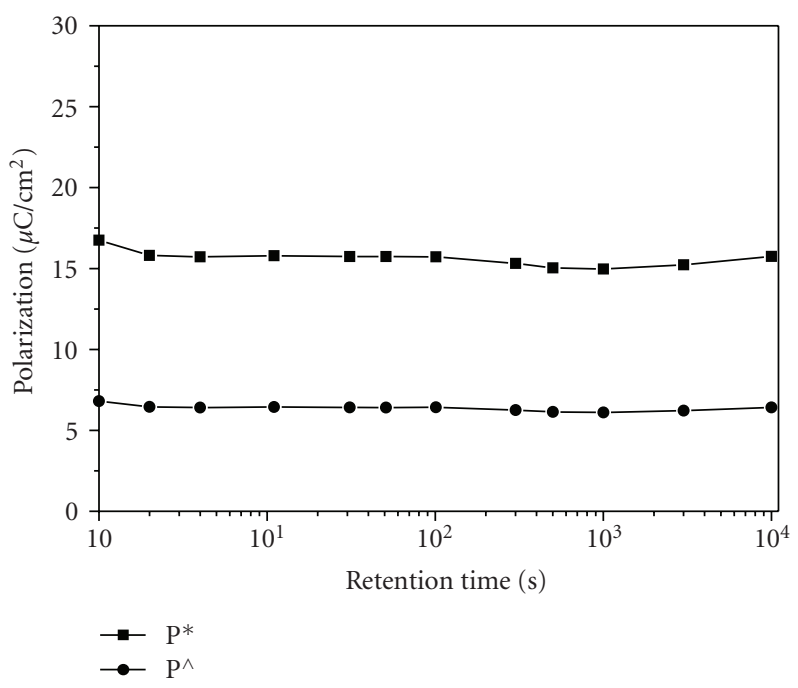

(b)

FIGURE 7: (a) Long-time retention characteristics at various electric fields ( 75 to $300 \mathrm{kV} / \mathrm{cm}$ ), and (b) the long-time retention characteristics $\left(\mathrm{P}^{*}\right.$ and $\left.\mathrm{P}^{\wedge}\right)$ measured at an applied electric field of $150 \mathrm{kV} / \mathrm{cm}$ for CBTil44 thin film deposited on (100) $\mathrm{Pt} / \mathrm{Ti} / \mathrm{SiO}_{2} / \mathrm{Si}$ substrate at $700^{\circ} \mathrm{C}$ for 2 hours.

the nature of those defects. Figure 7(a) shows the longtime retention characteristics of the CBT144 thin films annealed in static air. The retained switchable polarization $\left(\Delta \mathrm{P}=\mathrm{P}^{*}-\mathrm{P}^{\wedge}\right)$ was plotted as a function of retention time from $1 \mathrm{~s}$ to $10^{4} \mathrm{~s}$ at various electric fields from 75 to $300 \mathrm{kV} / \mathrm{cm}$. The high value of initial polarization decayed by about $10 \%$ and approached a nearly steady-state value after a retention time of $1 \mathrm{~s}$. The long-time retention characteristics $\left(\mathrm{P}^{*}\right.$ and $\left.\mathrm{P}^{\wedge}\right)$ of the CBTi144 films is shown in Figure 7(b). The overall retention time dependence of polarization retention for the CBTil44 film is quite good. After a retention time of $1 \times 10^{4} \mathrm{~s}$, the polarization loss was only about $7 \%$ of the value measured at $t=1.0 \mathrm{~s}$ for an applied electric field of $150 \mathrm{kV} / \mathrm{cm}$. Depolarization fields 
generated by the redistribution of space charge, defects, and dipole charges could be the mechanisms for the polarization decay after writing. For the infant period (within $10 \mathrm{~s}$ ), depolarization fields could be the main contribution to polarization loss. Similar retention loss behavior has been reported for $\mathrm{Bi}_{3.25} \mathrm{La}_{0.75} \mathrm{Ti}_{3} \mathrm{O}_{12}$ deposited on $\mathrm{Pt} / \mathrm{TiO}_{2} / \mathrm{SiO}_{2} / \mathrm{Si}$ [38]. Note that greater than $40 \%$ retention loss is often observed for various ferroelectric thin films after $10^{4} \mathrm{~s}$ even at room temperature [39]. Such behavior has been attributed to a depolarization field which can exist due to the incomplete compensation between the polarization charge and the free charge in the electrodes. The depolarization field raises with increasing the retained polarization and is time dependent. The long-time retention loss is attributed to the effects of redistribution of defect charges. This effect leads to a small decrease in the polarization by compensating the polarization charges when the redistribution of defect charges is driven by polarization. When $\mathrm{Ca}$ is added in the system, the $\mathrm{TiO}_{6}$ octahedra linked to $\mathrm{Bi}_{2} \mathrm{O}_{2}$ shrinks, restricting the movement of $\mathrm{Ti}^{4+}$ ions destroying the original functions of electrical insulation and space charge compensation. The oxygen vacancy acting as space charge will cause strong domain pinning and inhibits retention endurance. Oxygen vacancies neighboring bismuth ions are more likely inside the $\mathrm{Bi}_{2} \mathrm{O}_{2}$ layer than in the perovskite $\mathrm{BiTiO}_{3}$ structure. In the perovskite portion of the $\mathrm{Bi}_{4} \mathrm{Ti}_{3} \mathrm{O}_{2}$ structure, the $\mathrm{Bi}$ ion is placed in the center of the unit cell built by $\mathrm{Ti}$ cations. The oxygen anions form octahedral $\left(\mathrm{TiO}_{6}\right)$ enclosing the titanium ions. The $\mathrm{Bi}$ and $\mathrm{Ti}$ cations share oxygen atoms in the $\mathrm{BiTiO}_{3}$ unit cell and thus the strong Ti-O bonds in the perovskite lattice are not easily broken implying a nonrandom distribution of oxygen vacancies and their confinement inside the $\mathrm{Bi}_{2} \mathrm{O}_{2}$ layer.

The outstanding affinity of Ti towards oxygen could further explain the proposed CBTil44 defect structure. Taking into account that ferroelectric responses of the $\mathrm{Bi}$ layered perovskite materials are originated mainly from metal-oxygen octahedra, we argue that retention failures of CBTi144 films should be related to the oxygen vacancies present at the titanium-oxygen octahedra. These experimental results imply that oxygen vacancies could be induced in the neighborhood of the $\mathrm{Bi}$ and the $\mathrm{Ti}$ ions in BIT. Therefore, the oxygen atom in the stronger $\mathrm{Ti}-\mathrm{O}$ bond carries a higher effective negative charge than in a weaker $\mathrm{Bi}-\mathrm{O}$ bond. So compared with $\mathrm{Bi}-\mathrm{O}$ bond, $\mathrm{Ti}-\mathrm{O}$ bond is not easily broken by calcium addition. The electronic structure of $\left[\mathrm{TiO}_{6}\right]$ is favored by three factors: lack of oxygen vacancies, small amount of calcium ions for charge compensation, and abundance of complexes defect. Detailed retention measurements in close correlation with process conditions will be done to evaluate the merits of calcium bismuth titanate thin films for memory applications.

\section{Conclusions}

In summary, we investigated the nature of defects on retention characteristics of CBTi144 thin film obtained by the soft chemical method. The characteristic orientation of the CBTi144 thin film is considered to be due to good matching of atomic arrangements in CBTi144 (100)/(010) and underlying $\mathrm{Pt}$ planes. The film also consists of welldeveloped and uniform columnar grains of perovskite phase. FT-IR reflectance spectra confirmed a stronger metal-oxygen octahedral vibrational mode. XPS data indicates that the substitution of calcium in the A site have influence in the concentration of oxygen vacancies in the vicinity of $\mathrm{Bi}$ and Ti ions. Retention failure tests pointed to that the CBT144 films have quite good long-time retention characteristics, retaining $90 \%$ of the values measured at $t=1 \mathrm{~s}$. The oxygen environment in the CBTil44 lattice is the main source of retention-free characteristic of the ferroelectric capacitors.

\section{Acknowledgment}

The financial support from the Brazilian agencies FAPESP, $\mathrm{CNPq}$, and CAPES is gratefully acknowledged.

\section{References}

[1] W. Di, L. Aidong, Z. Tao, L. Zhiguo, and N. Ming, "Ferroelectric properties of $\mathrm{Bi}_{3.25} \mathrm{La}_{0.75} \mathrm{Ti}_{3} \mathrm{O}_{12}$ thin films prepared by chemical solution deposition," Journal of Applied Physics, vol. 88, no. 10, pp. 5941-5945, 2000.

[2] Y. Adachi, D. Su, P. Muralt, and N. Setter, "Ferroelectric and piezoelectric properties of lanthanoid-substituted $\mathrm{Bi}_{4} \mathrm{Ti}_{3} \mathrm{O}_{12}$ thin films grown on (111)Pt and (100) $\mathrm{IrO}_{2}$ electrodes," Applied Physics Letters, vol. 86, no. 17, Article ID 172904, pp. $1-3,2005$.

[3] S.-K. Kim, M. Miyayama, and H. Yanagida, "Electrical anisotropy of $\mathrm{BaBi}_{4} \mathrm{Ti}_{4} \mathrm{O}_{15}$ single crystal," Journal of the Ceramic Society of Japan, vol. 102, pp. 722-726, 1994.

[4] S.-K. Kim, M. Miyayama, and H. Yanagida, "Complex impedance and modulus analysis on electrical anisotropy of layer-structured $\mathrm{BaBi}_{4} \mathrm{Ti}_{4} \mathrm{O}_{15}$ single crystal in paraelectric phase," Journal of the Ceramic Society of Japan, vol. 103, no. 1195, pp. 315-318, 1995.

[5] I. Yi and M. Miyayama, Transactions of the Materials Research Society of Japan, vol. 20, p. 660, 1996.

[6] Y.-I. Park, M. Miyayama, and T. Kudo, "Fabrication of $\mathrm{PbBi}_{4} \mathrm{Ti}_{4} \mathrm{O}_{15}$ and $\mathrm{Pb}_{2} \mathrm{Bi}_{4} \mathrm{Ti}_{5} \mathrm{O}_{18}$ thin films by sol-gel method," Journal of the Ceramic Society of Japan, vol. 107, no. 5, pp. 413418, 1999.

[7] H. Watanabe, T. Mihara, H. Yoshimori, and Carlos A. Paz de Araujo, "Preparation of ferroelectric thin films of bismuth layer structured compounds," Japanese Journal of Applied Physics, Part 1, vol. 34, no. 9, pp. 5240-5244, 1995.

[8] E. C. Subbarao, "Crystal chemistry of mixed bismuth oxides with layer-type structure," Journal of the American Ceramic Society, vol. 45, pp. 166-169, 1962.

[9] L. Korzanova, Ferroelectrics, vol. 134, p. 175, 1992.

[10] W. X. Xianyu, W. I. Lee, T. Ko, and J. K. Lee, "Ferroelectric behavior of orientation-controlled $\mathrm{PbBi}_{4} \mathrm{Ti}_{4} \mathrm{O}_{15}$ thin films," Applied Physics Letters, vol. 82, no. 20, pp. 3496-3498, 2003.

[11] A. Garg, Z. H. Barber, M. Dawber, J. F. Scott, A. Snedden, and P. Lightfoot, "Orientation dependence of ferroelectric properties of pulsed-laser-ablated $\mathrm{Bi}_{4-x} \mathrm{Nd}_{x} \mathrm{Ti}_{3} \mathrm{O}_{12}$ films," Applied Physics Letters, vol. 83, no. 12, pp. 2414-2416, 2003.

[12] K. Kato, K. Suzuki, D. Fu, K. Nishizawa, and T. Miki, "Platinum-assisted phase transition in bismuth-based 
layer-structured ferroelectric $\mathrm{CaBi}_{4} \mathrm{Ti}_{4} \mathrm{O}_{15}$ thin films," Applied Physics Letters, vol. 81, no. 17, pp. 3227-3229, 2002.

[13] K. Kato, K. Suzuki, K. Nishizawa, and T. Miki, "Ferroelectric properties of alkoxy-derived $\mathrm{CaBi}_{4} \mathrm{Ti}_{4} \mathrm{O}_{15}$ thin films on Ptpassivated Si," Applied Physics Letters, vol. 78, no. 8, pp. 1119 1121, 2001.

[14] K. Kato, K. Suzuki, K. Nishizawa, and T. Miki, "Comparison of microstructure and ferroelectric properties of alkoxy-derived $\mathrm{MBi}_{4} \mathrm{Ti}_{4} \mathrm{O}_{15}$ (M: Ca or $\mathrm{Sr}$ ) thin films," Japanese Journal of Applied Physics, Part 1, vol. 40, no. 9 B, pp. 5580-5584, 2001.

[15] T. Takeuchi, T. Tani, and Y. Saito, "Piezoelectric properties of bismuth layer-structured ferroelectric ceramics with a preferred orientation processed by the reactive templated grain growth method," Japanese Journal of Applied Physics, Part 1, vol. 38, no. 9, pp. 5553-5556, 1999.

[16] T. Takeuchi, T. Tani, and Y. Saito, "Unidirectionally textured $\mathrm{CaBi}_{4} \mathrm{Ti}_{4} \mathrm{O}_{15}$ ceramics by the reactive templated grain growth with an extrusion," Japanese Journal of Applied Physics, Part 1, vol. 39, no. 9, pp. 5577-5580, 2000.

[17] V. Samuel, A. B. Gaikwad, A. D. Jadhav, S. A. Mirji, and V. Ravi, "A novel technique to prepare $\mathrm{CaBi}_{4} \mathrm{Ti}_{4} \mathrm{O}_{15}$ at low temperature," Materials Letters, vol. 61, no. 3, pp. 765-766, 2007.

[18] H. Muthurajan, H. H. Kumar, N. Natarajan, and V. Ravi, "A novel technique to prepare $\mathrm{LiTaO}_{3}$ at low temperature," Ceramics International, vol. 34, no. 3, pp. 669-670, 2008.

[19] H. Muthurajan, H. H. Kumar, V. Samuel, U. N. Gupta, and V. Ravi, "Novel hydroxide precursors to prepare $\mathrm{NaNbO}_{3}$ and $\mathrm{KNbO}_{3}$," Ceramics International, vol. 34, no. 3, pp. 671-673, 2008.

[20] H. Muthurajan, N. K. Rao, U. N. Gupta, et al., "Novel hydroxide precursors for low temperature synthesis of selected ternary oxides," Materials Research Bulletin, vol. 43, no. 7, pp. 1842-1849, 2008.

[21] U. N. Gupta, H. Muthurajan, H. H. Kumar, N. K. Rao, S. P. Gokhale, and V. Ravi, "Synthesis of LSMO at low temperature by novel hydroxide precursor technique," Materials Letters, vol. 62, no. 3, pp. 527-529, 2008.

[22] H. Muthurajan, H. H. Kumar, N. K. Rao, S. Pradhan, R. K. Jha, and V. Ravi, "Low temperature synthesis of $\mathrm{SrNb}_{2} \mathrm{O}_{6}$ and $\mathrm{SrTa}_{2} \mathrm{O}_{6}$ using hydroxide precursor," Materials Letters, vol. 62, no. 6-7, pp. 892-894, 2008.

[23] U. N. Gupta, V. Samuel, H. Muthurajan, H. H. Kumar, S. D. Patil, and V. Ravi, "A co-precipitation method for preparation of $\mathrm{Bi}_{3} \mathrm{TiNbO}_{9}$ powders," Ceramics International, vol. 34, no. 3 , pp. 675-677, 2008.

[24] A. Z. Simões, A. H. Gonzalez, C. S. Riccardi, et al., "Effect of magnesium on the properties of $\mathrm{LiNbO}_{3}$ thin films prepared from polymeric precursors," Integrated Ferroelectrics, vol. 43, pp. 123-135, 2002.

[25] A. Z. Simões, A. H. Gonzalez, M. A. Zaghete, et al., "Influence of oxygen flow on crystallization and morphology of $\mathrm{LiNbO}_{3}$ thin films," Ferroelectrics, vol. 271, pp. 33-38, 2002.

[26] B. H. Park, S. J. Hyun, S. D. Bu, et al., "Differences in nature of defects between $\mathrm{SrBi}_{2} \mathrm{Ta}_{2} \mathrm{O}_{9}$ and $\mathrm{Bi}_{4} \mathrm{Ti}_{3} \mathrm{O}_{12}$," Applied Physics Letters, vol. 74, no. 13, pp. 1907-1909, 1999.

[27] E. R. Leite, C. M. G. Sousa, E. Longo, and J. A. Varela, "Influence of polymerization on the synthesis of $\mathrm{SrTiO}_{3}$ : part I. Characteristics of the polymeric precursors and their thermal decomposition," Ceramics International, vol. 21, no. 3, pp. 143-152, 1995.
[28] C. A-Paz de Araujo, J. D. Cuchlaro, L. D. McMillan, M. C. Scott, and J. F. Scott, "Fatigue-free ferroelectric capacitors with platinum electrodes," Nature, vol. 374, no. 6523, pp. 627-629, 1995.

[29] P. C. Joshi, S. B. Krupanidhi, and A. Mansingh, "Rapid thermally processed ferroelectric $\mathrm{Bi}_{4} \mathrm{Ti}_{3} \mathrm{O}_{12}$ thin films," Journal of Applied Physics, vol. 72, no. 11, pp. 5517-5519, 1992.

[30] C. Jovalekic, M. Pavlovic, P. Osmokrovic, and L. Atanasoska, "X-ray photoelectron spectroscopy study of $\mathrm{Bi}_{4} \mathrm{Ti}_{3} \mathrm{O}_{12}$ ferroelectric ceramics," Applied Physics Letters, vol. 72, no. 9, pp. 1051-1053, 1998.

[31] B. H. Park, S. J. Hyun, S. D. Bu, et al., "Differences in nature of defects between $\mathrm{SrBi}_{2} \mathrm{Ta}_{2} \mathrm{O}_{9}$ and $\mathrm{Bi}_{4} \mathrm{Ti}_{3} \mathrm{O}_{12}$," Applied Physics Letters, vol. 74, no. 13, pp. 1907-1909, 1999.

[32] B. S. Kang, B. H. Park, S. D. Bu, S. H. Kang, and T. W. Noh, "Different fatigue behaviors of $\mathrm{SrBi}_{2} \mathrm{Ta}_{2} \mathrm{O}_{9}$ and $\mathrm{Bi}_{3} \mathrm{TiTaO}_{9}$ films: role of perovskite layers," Applied Physics Letters, vol. 75, no. 17, pp. 2644-2646, 1999.

[33] A. Z. Simões, M. A. Ramırez, A. H. M. Gonzalez, et al., "Control of retention and fatigue-free characteristics in $\mathrm{CaBi}_{4} \mathrm{Ti}_{4} \mathrm{O}_{15}$ thin films prepared by chemical method," Journal of Solid State Chemistry, vol. 179, no. 7, pp. 2206-2211, 2006.

[34] J. T. Last, "Infrared-absorption studies on barium titanate and related materials," Physical Review, vol. 105, no. 6, pp. 17401750, 1957.

[35] K. Kato, K. Suzuki, K. Nishizawa, and T. Miki, "Comparison of microstructure and ferroelectric properties of alkoxy-derived $\mathrm{MBi}_{4} \mathrm{Ti}_{4} \mathrm{O}_{15}$ (M: Ca or Sr) thin films," Japanese Journal of Applied Physics, Part 1, vol. 40, no. 9, pp. 5580-5584, 2001.

[36] A. Z. Simões, C. S. Riccardi, M. A. Ramırez, L. S. Cavalcante, E. Longo, and J. A. Varela, "Synthesis and characterization of $\mathrm{CaBi}_{4} \mathrm{Ti}_{4} \mathrm{O}_{15}$ thin films annealed by microwave and conventional furnaces," Solid State Sciences, vol. 9, no. 8, pp. 756-760, 2007.

[37] K. Kato, K. Suzuki, K. Nishizawa, and T. Miki, "Ferroelectric properties of alkoxy-derived $\mathrm{CaBi}_{4} \mathrm{Ti}_{4} \mathrm{O}_{15}$ thin films on Ptpassivated Si," Applied Physics Letters, vol. 78, no. 8, pp. 11191121, 2001.

[38] B. S. Kang, J. G. Yoon, T. K. Song, S. Seo, Y. W. So, and T. W. Noh, "Retention characteristics of $\mathrm{Bi}_{3.25} \mathrm{La}_{0.75} \mathrm{Ti}_{3} \mathrm{O}_{12}$ thin films," Japanese Journal of Applied Physics, Part 1, vol. 41, no. 8, pp. 5281-5283, 2002.

[39] J. W. Hong, W. Jo, D. C. Kim, et al., "Nanoscale investigation of domain retention in preferentially oriented $\mathrm{PbZr}_{0.53} \mathrm{Ti}_{0.47} \mathrm{O}_{3}$ thin films on Pt and on $\mathrm{LaNiO}_{3}$," Applied Physics Letters, vol. 75, no. 20, pp. 3183-3185, 1999. 

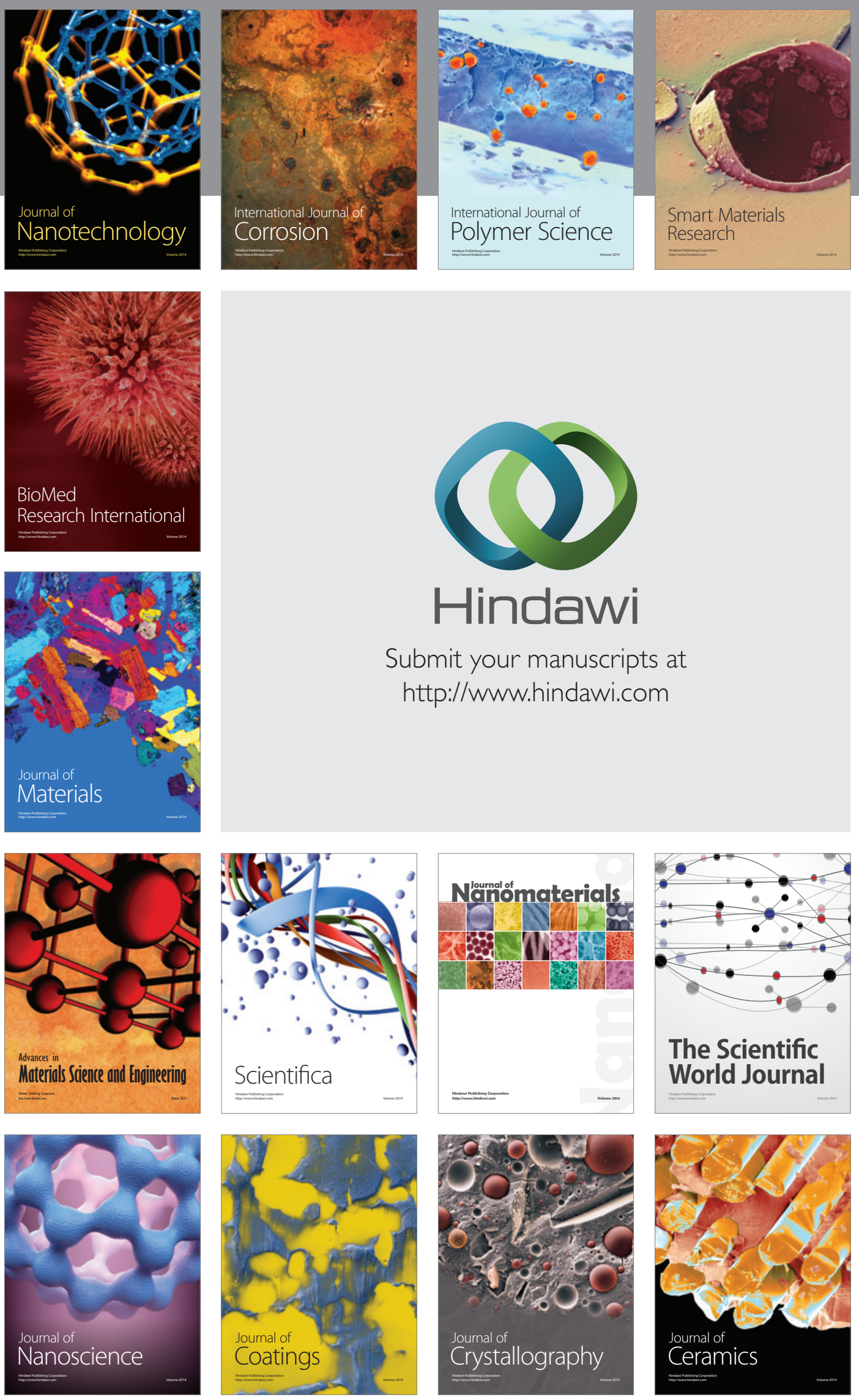

The Scientific World Journal

Submit your manuscripts at

http://www.hindawi.com

\section{World Journal}

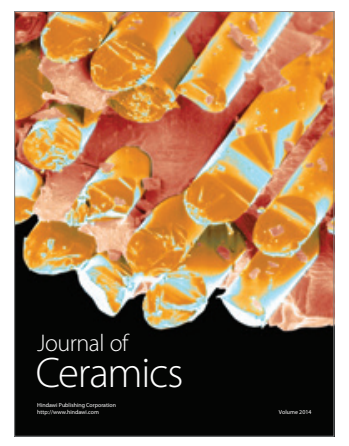

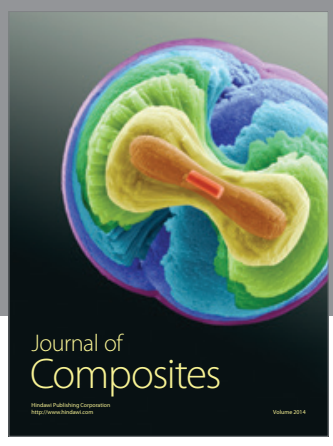
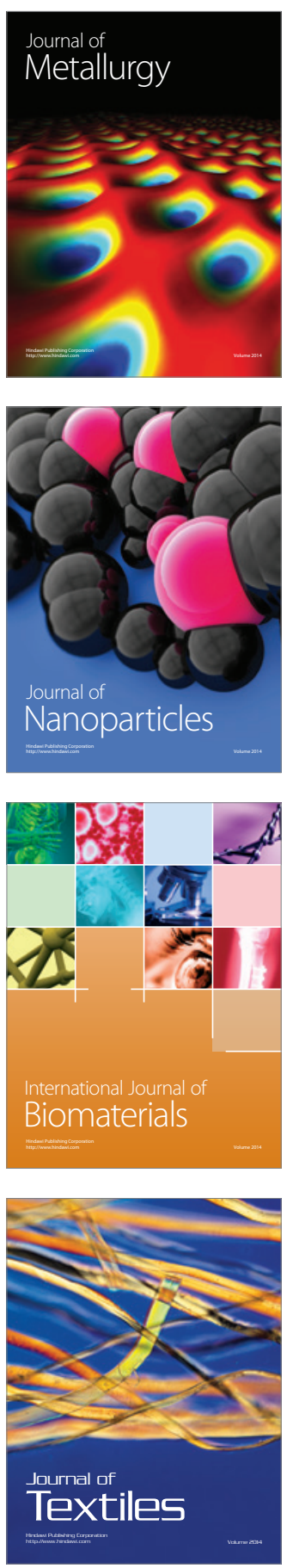